\title{
Sharing the Ideas of Meta - Science to Improve Quality of Research
}

\author{
Aryal UR, ${ }^{1}$ Khanal $\mathrm{K}^{2}$
}

Department of Community Medicine

${ }^{1}$ Kathmandu Medical College

${ }^{2}$ Kathmandu University School of Medical Sciences Dhulikhel, Kavre, Nepal

\section{Corresponding Author}

Umesh Raj Aryal

Department of Community Medicine

Kathmandu Medical College

E-mail: aryalumesh@gmail.com

\begin{abstract}
Meta-Science is an interdisciplinary science which provides plenty of oppurtunity to cooperate on better understanding of micro-social dimension of science. It plays vital role to justify the conclusion, which helps to improve quality of research as well as to health services. There are various applications of meta-science for improving quality of research namely: applying theories of philosophy and different disciplines, the use of triangulation, inductive and deductive reasoning, ethical issues and finally fundamentals of scientific research.
\end{abstract}

\section{KEY WORDS}

Meta-Science, quality of research

Citation

Aryal UR, Khanal K. Sharing the Ideas of Meta Science to Improve Quality of Research. Kathmandu Univ Med J 2013;41(1):75-77.

\section{INTRODUCTION}

Meta-Science is a theory of science or science about science which is developed from interdisciplinary sciences which includes theorists of science; theorists of sociology; historians of science; and psychologists of science. ${ }^{1,2}$ It provides plenty of oppurtunity to cooperate on better understanding of micro-social dimension of science. To understand micro-social dimension, one needs both psychologically and sociologically realistic model of the research process. ${ }^{1,2}$

In scientific research process, scientific knowledge and vital problems plays significant role than the answer. The scientific knowledge helps them to justify their conclusions. Such a conclusion can be made with the help of meta- science. Therefore, it is essential to improve quality of research as well as to improve health services in the country. ${ }^{2}$

\section{Application of Meta Science}

The following paragraphs illustrates application of metascience for improving quality of research in any country including Nepal.

First, Identification of research problems is very important when researcher want to conduct research. ${ }^{2}$ There is no clear cut definition about meaning of research problems. It depends upon the knowledge of researcher where he needs to develop conceptual framework. The researcher should not only speak about the development of research questions but also include devlopment of preunderstanding used. When researchers define the research problems, they need to explain it in three ways: 1) qualities of formulation which explains the limitation of the research problems. 2) qualities of phenomena which 
describes problem related approach either empirical or theoritical. 3) solution which illustrates the methods applied to solve the research problems either qualitative or quantitiative. ${ }^{2}$ There are several conditions for development of the research problems i.e. cognitive; time; money and goal setting. They are also able to generate reseach problems from early experiences; interest of researcher; problem formulation and dialogue; intra- and inter-disciplinary conditions; researcher and practicians meet together; research grant applications. ${ }^{2}$ They also need to know "how to solve conflict of interest in your research work". Before identification of the problems, the researchers should be aware about the philosophy of science such as Karl Popper and historians of science Thomas Kuhn which are very important to understand the early view of research problems. Popper(1972) stated Problems $(\mathrm{P})>$ Tentative Theories(TT) $>$ Error Ellimination(EE) through rational criticism or empirical testing. Kuhn(1970) pointed out that what we see depends upon on what we look at and what previous visual-conceptual experiences have taught us to see. ${ }^{2}$

Second, the research should be conducted by applying theories of philosophy and different disciplines. Here we would like to illustrates with an example. It is often said "writing presceptions is easy but otherwise coming to an understanding with people is hard". ${ }^{3}$ It means just giving treatment to the patient is not sufficient but it is necessary to understand both objective and subjective feeling to improve more than one things in the patient. Good general practice of medicine is always based on evidence whenever appropriate and possible. ${ }^{4}$ The question is what form of evidence can do justice for the patient? As we understand the first need is the objective evidence about harm to patients from certain diseases. Second, doctors need to generate evidence about hidden and interconnected things in patients such as their society and culture. ${ }^{4}$ It is widely discussed on literature of Community Medicine, Public Health Science, Medical Sociology and Anthropology .

Evidence is a knowledge generated from competent inquiry. ${ }^{4}$ Evidence are usually asscoiated with positivism or quantitative research where hypothesis are generated and tested with controlling the situations. ${ }^{4}$ The practice of positivism is very common in medical doctors and in other health professionals. Positivism workswell instable situation but not in complex and changing situation. We understand society is changing day by day and the changing situation is uncertain. Thus, creative aspects of role of doctors can be utlized not only by positivist theory of knowledge but also from critical theory and constructivism. ${ }^{4}$ All these theories are applied in clinical research by diagnose, listening and reflecting to improve medical practice. When the doctors want to do positivism study, he has to adopts ontology(our assumptions about how the world is made up and the nature of things); epistemology(our beliefs about how one might discover knowledge about the world); and methodology (the tools and techniques of research). Critical theory is the exmination and the critique of positivism by applying knowledge from social science. ${ }^{5}$ Innovation and novelty are best understood through theory of knowledge termed as constructism. It reveals the cocreative nature of innovation. For example, idea of television is based on the cobmination of idea of photography and radiowave. ${ }^{4}$ Finally, it is clear that knowing the three different kinds of knowledge helps to improve research quality for doctors and other health professionals. ${ }^{4}$

Third , the use of triangulation or mixed methods is another approach to improve quality of research. ${ }^{5}$ The most common methods is combination of both quantitative and qualitative methods in a single study from primary and secondary sources. ${ }^{5}$ It increases the credibility and validity of the results through cross-checking approach from more than two sources. ${ }^{5}$ It can involves the use of a variety of data sources (data triangulation); the use of several different researchers (investigator triangulation); the use of multiple perspectives to interpret the results (theory triangulation); the use of multiple methods to study a research problem (methodological triangulation). ${ }^{5}$ There are number of empirical examples of triangulation and mixed methods which can be learned through experience of crossdisciplinary collaboration. (a) During mediaeval times could come to the conclusion that the earth was flat with 100 s of methods but it is still wrong. ${ }^{1,6}(\mathrm{~b})$. Epidemiologists saw that there was something wrong with the feeding of children in Brazil, but could not explain why. ${ }^{7}$ When anthropologists made interviews with doctors and women they found that reason that it was a document from US that was used as a norm for weight also for kids from Brazil. Two different methods will sometimes give different results but the first case give "exact knowledge", the other an "understanding" of what is going on. ${ }^{7}$

Fourth, both inductive and deductive reasoning can be applied to improve quality of research. Inductive reasoning are bottom-up approach and deductive reasoning topdown approach. Bankok charter has focused on top-down approach which explains to develop theory based on observation. ${ }^{8}$ Now-a-days, grounded theories, combination of both approach are practiced among reseachers to generate theories from the data rather the other way around. $^{5}$

Fifth, ethical issues are another important aspects to improve quality of data. Reseachers need to focus on ethics because the facts do not always tell us what to do. ${ }^{3}$ Researchers should be familier with ethical framework and theoritical approaches and how to apply them in their research process. The principlist approach has four principals i.e. benefience;non-malefience;respect of autonomy; and justice. ${ }^{3}$ There are ethical theories based on the ethical principles which brings significant characteristics to the decision-making process. These theories are: ${ }^{3}$

1. Deontology( related with duty);2) Consequentialism (right 
action in situation should be based on the consequences); 3) Virtue ethics (understand the importance of sensibility to the context)

When researchers understand each theory, including its strengths and weaknesses, he/she can make the most informed decision when trying to achieve an ethically correct answer to a dilemma. ${ }^{3}$

Lastly, the researcher should also follow the fundamentals of scientific research. These fundamentals includes scientific honestly; carefulness; Intellectual freedom;Openness(allow public to see your work for criticism; the principal of credit; the principle of public responsibility (dissimination). ${ }^{1,9}$

\section{REFERENCE}

1. Bärmark J, Thorpenberg S. [Unpublished lecture notes on Theory of Science,Kathmandu].University of Gothenburg, Sweden.notes provided at lecture 2012 November 26-30.

2. Allwood CM, Bärmark J. The Role of Research Problems in the Process of Research. Social Epistemology 1999; 13(1): 59-83.

3. Gillies CM. Ethics in primary care: theory and practice. InnovAiT 2009;2(3): 183-190.

4. Thomas P. General medical practitioners need to be aware of the theories on which our work depend. The Annals of Family Medicine 2006; 4( 5): 450-454.

5. Joshi SP. Qualitative Research: Approaches for health personnel. First Edition. Makalu Publication House, Kathmandu, Nepal: 2008.

\section{CONCLUSION}

In the era of evidence based medicine, above mentioned ideas are indispensable to understand by health professionals who wants to conduct and promote scientific research. Further, it also helps to improve quality of research in the country.

\section{ACKNOWLEDGEMENT}

We would like to thank Professor Jan Bärmark, Theory of Science and Stefan Thorpenberg, Associate Professor Research Policy at University of Gothenburg, Sweden for their valuable suggestion and input.

6. Wikipedia. Flat Earth [cited on 21 December 2012]. Available on http://en.wikipedia.org/wiki/Main_Page.

7. Béhague D. P., Gonçalves H, Victora C. G. Anthropology and Epidemiology: learning epistemological lessons through a collaborative venture. Ciencia and saude coletiva 13(6):1701-1710.

8. Thorpenberg, Stefan. Alcohol health promotion research and policy in the Nordic countries-a literature. Science Studies 2010.23 (1): 79-95.

9. Resnik, D. Philosophical foundations of scientific ethics [cited on 22 December 2012]. Available on http://people.emich.edu/jthomsen/ Ethics/proceedings/Resnik1.pdf. 